\title{
Developing Therapeutic Approaches to Tau, Selected Kinases, and Related Neuronal Protein Targets
}

\author{
Virginia M-Y. Lee ${ }^{1}$, Kurt R. Brunden ${ }^{1}$, Michael Hutton ${ }^{2}$, and John Q. Trojanowski ${ }^{1}$ \\ ${ }^{1}$ Center for Neurodegenerative Disease Research, Institute on Aging, Department of Pathology and Laboratory \\ Medicine, School of Medicine, University of Pennsylvania, Philadelphia, Pennsylvania 19104 \\ ${ }^{2}$ Eli Lilly and Co., Indianapolis, Indiana 46285 \\ Correspondence: kbrunden@upenn.edu
}

\begin{abstract}
A hallmark of the Alzheimer disease (AD) brain is the presence of inclusions within neurons that are comprised of fibrils formed from the microtubule-stabilizing protein tau. The formation of misfolded multimeric tau species is believed to contribute to the progressive neuron loss and cognitive impairments of AD. Moreover, mutations in tau have been shown to cause a form of frontotemporal lobar degeneration in which tau neuronal inclusions observed in the brain are similar to those seen in AD. Here we review the more compelling strategies that are designed to reduce the contribution of misfolded tau to $\mathrm{AD}$ neuropathology, including those directed at correcting a possible loss of tau function resulting from sequestration of cellular tau and to minimizing possible gain-of-function toxicities caused by multimeric tau species. Finally, we discuss the challenges and potential benefits of tau-directed drug discovery programs.
\end{abstract}

\section{INTRODUCTION TO TAU PATHOLOGY AND GENETICS}

The he Alzheimer disease (AD) brain contains two key pathological features that are used to make a definitive diagnosis; extracellular deposits referred to as senile plaques, and neuronal intracellular inclusions called neurofibrillary tangles (NFTs). As discussed in detail in other articles of this volume, senile plaques are comprised of fibrils of amyloid $\beta$ (A $\beta$ ) peptides (Glenner and Wong 1984) that are formed during proteolytic processing of the amyloid precursor protein (APP) (Kang et al. 1987). Here we focus on the other hallmark of the Alzheimer disease (AD) brain, the NFTs that are formed from insoluble fibrils of tau protein (Kidd 1963; Lee et al. 1991). More specifically, we review the likely involvement of misfolded tau in the neurodegeneration and memory impairments observed in $\mathrm{AD}$, and present possible therapeutic strategies to ameliorate tau-mediated pathology.

Tau is highly enriched within neurons of the central nervous system, in which it appears to play an important role in the formation and stabilization of microtubules (MTs) (Drechsel et al. 1992; Gustke et al. 1994). MTs are critical to neuronal function, serving as conduits on

Editors: Dennis J. Selkoe, David M. Holtzman, and Eckhard Mandelkow

Additional Perspectives on The Biology of Alzheimer Disease available at www.perspectivesinmedicine.org

Copyright (C) 2011 Cold Spring Harbor Laboratory Press; all rights reserved; doi: 10.1101/cshperspect.a006437

Cite this article as Cold Spring Harb Perspect Med 2011;1:a006437 
V.M-Y. Lee et al.

which key cellular components are transported along axons. In the human CNS, there are six major tau isoforms that are generated by differential splicing of exons 2, 3, and 10 of the tau transcript (Fig. 1) (Goedert et al. 1989; Andreadis et al. 1992). The inclusion or exclusion of exon 10 results in tau species that contain either four (4-R) or three (3-R) microtubule-binding repeats, respectively, with the ratio of $3-\mathrm{R}$ to- $4-\mathrm{R}$ tau being $\sim 1$ in the normal brain (Hong et al. 1998). In AD and other related neurodegenerative "tauopathies," which include Pick's disease, progressive supranuclear palsy (PSP), and corticobasal degeneration (CBD), misfolded and hyperphosphorylated tau accumulates as insoluble fibrils primarily within neuronal cell bodies (as NFTs) and in processes (as neuropil threads or dystrophic neurites), but also as tau inclusions in astrocytes and microglia (Lee et al. 2001; Ballatore et al. 2007b). The presence of tau inclusions in $\mathrm{AD}$ and a large number of other neurodegenerative tauopathies suggests that these deposits somehow contribute to development of synaptic deficits and neuronal loss. In fact, cortical NFT density correlates well with cognitive decline in $\mathrm{AD}$ unlike senile plaque burden (Wilcock and Esiri 1982; Braak and Braak 1991; Arriagada et al. 1992; Gomez-Isla et al. 1997), which occurs early and appears to reach a plateau prior to the onset of clinical symptoms. Indeed, $\sim 90 \%$ of the tau pathology burden in $\mathrm{AD}$ is in dystrophic neurites so that tangle counts underestimate the total burden of tau pathology (Mitchell et al. 2000). Proof that altered tau function and/ or structure can cause neurodegeneration has
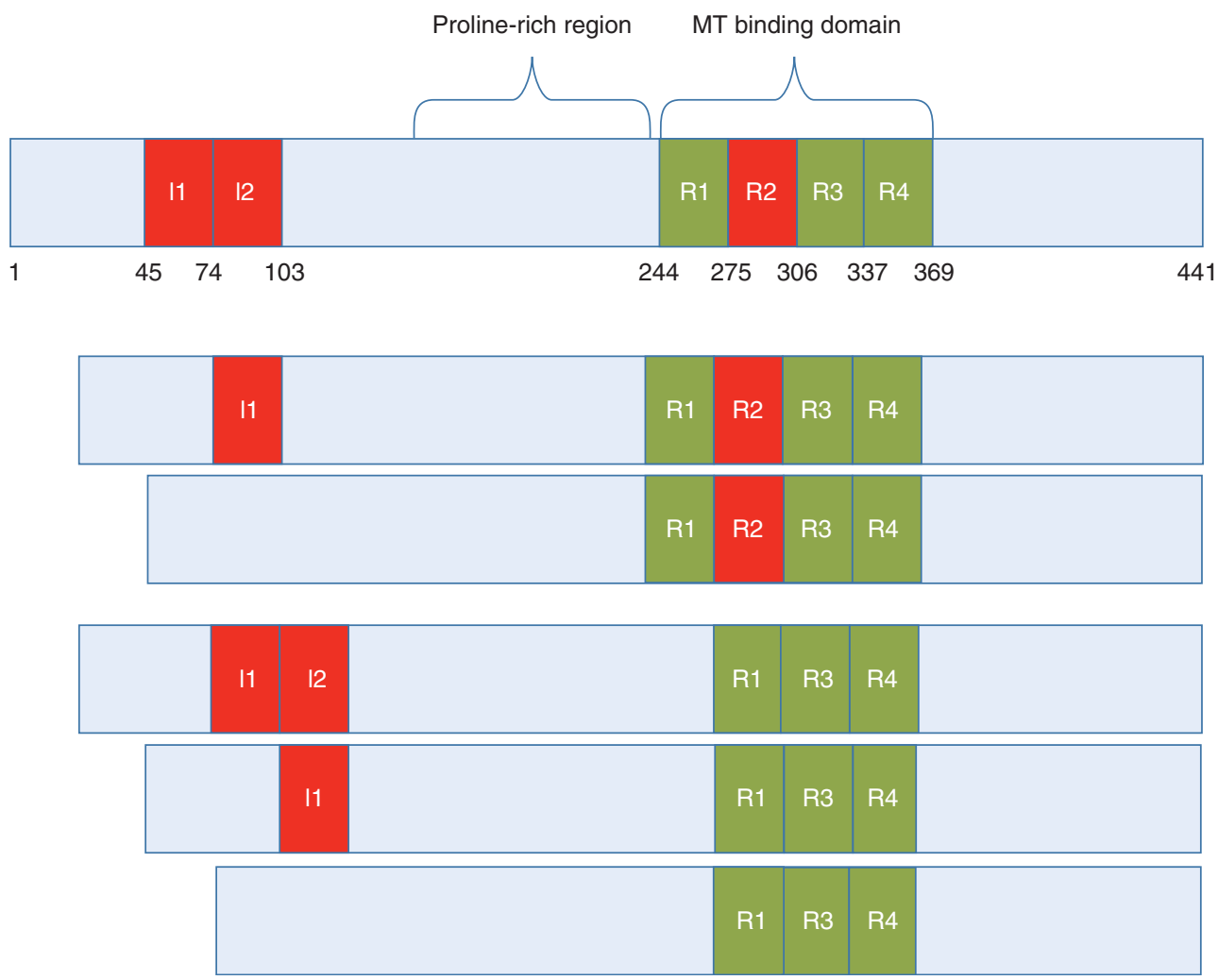

Figure 1. Schematic of the longest human tau isoform and the other major tau isoforms found in humans that are generated through posttranscriptional splicing of exons 2 (I1), 3 (I2), and 10 (R2). The inclusion or exclusion of exon 10 results in tau with four or three binding repeats within the MT binding domain (4R-tau or 3R-tau), respectively. Amino acid numbers are depicted along the bottom of the longest tau isoform. 
been provided by the discovery that Frontotemporal Dementia with Parkinsonism linked to Chromosome 17 (FTDP-17) results from mutations in the tau gene (Hong et al. 1998; Hutton et al. 1998). Although there are no reported tau mutations in $\mathrm{AD}$, the similarities in tau pathology observed in the various tauopathies suggests that tau plays a pivotal role mediating neurodegeneration in all of these diseases.

The tau mutations observed in FTDP-17 fall into two general classes; those that affect the splicing of exon 10, such that the 4-R-to$3-\mathrm{R}$ tau ratio is increased, and those that alter tau structure and function. The latter are predominantly located within the MT-binding domains (Goedert and Jakes 2005). These FTDP-17 mutations offer an opportunity to understand how tau alterations might lead to neurodegeneration, and current tau gain-of-function and loss-of-function hypotheses, as discussed further below, have resulted largely from studies of mutated tau. For example, it is known that 4-R tau binds MTs more avidly than 3-R tau (Panda et al. 2003), and thus FTDP-17 mutations that result in increased $4-\mathrm{R}$ tau because of altered splicing of exon 10 (Hong et al. 1998) might lead to an overstabilization of MTs with resulting axonal dysfunction. Conversely, FTDP-17 mutations within the MT-binding domains of tau generally reduce the binding of tau to MTs (Hasegawa et al. 1998; Hong et al. 1998; Dayanandan et al. 1999), perhaps leading to a destabilization of MTs. In addition, mutations that reduce tau binding to MTs could increase the concentration of unbound tau and thus promote the formation of tau multimers and fibrils that have been proposed to elicit a direct toxic effect on neurons. Many of the tau coding-region mutations in FTDP-17 also promote enhancement of tau oligomerization and fibrillization (Hong et al. 1998; Nacharaju et al. 1999; Barghorn et al. 2000; Avila et al. 2006). Finally, in vitro tau assembly studies have suggested that under reducing conditions, $4 \mathrm{R}$ tau forms fibrils more readily than 3R tau (Barghorn and Mandelkow 2002; Jeganathan et al. 2008). As a reducing environment is generally maintained in cells, the exon 10 splicing mutations that increase $4 \mathrm{R}$ tau may also accelerate tau aggregation in patients. This observation may provide a simple explanation of why the two types of tau mutations that appear to have opposing effects on microtubule binding result in a broadly similar clinical and pathological syndrome.

Although the FTDP-17 mutations provide important evidence that tau misfolding and multimerization can lead to neurodegeneration, the absence of tau mutations in AD suggests that other tau changes and/or factor(s) are required to initiate tau pathogenesis in this disease. For example, posttranslational phosphorylation of tau appears to cause structural and functional changes that mimic those observed with FTDP-17 mutations and tau proteins isolated from paired helical filaments (PHFs) from AD brains do not bind to MTs unless they are dephosphorylated (Bramblett et al. 1993). The ability to recapture MT binding on dephosphorylation provides evidence that modulation of tau phosphorylation may be a viable therapeutic strategy. Tau is phosphorylated at multiple serine (ser) and threonine (thr) residues (Buee et al. 2000; Avila 2006), and increased phosphorylation at many of these sites results in reduced tau binding to MTs (Alonso et al. 1996; Wagner et al. 1996; Merrick et al. 1997) and/or a greater propensity for tau to assemble into fibrils (Alonso et al. 1996; Necula and Kuret 2004). However, phosphorylation at certain sites prevents tau fibrillization (Schneider et al. 1999), and there is thus greater consensus that the primary effect of tau hyperphosphorylation is to decrease MT binding and increase the cytosolic tau concentration (Ballatore et al. 2007b; Brunden et al. 2009). In general, the extent to which posttranslational phosphorylation contributes to the onset of tau pathology in AD is still uncertain, as tau hyperphosphorylation is also observed in FTDP-17, in which tau mutations are presumably responsible for the development of pathology.

Tau can also be modified through the addition of $\beta$-N-acetylglucosamine (O-GlcNac) at certain ser and thr phosphorylation sites, and there is evidence that increased O-GlcNac modification of tau results in a corresponding decrease in phosphorylation (Lefebvre et al. 2003; Liu et al. 2004). Tau can also undergo 
V.M-Y. Lee et al.

tyrosine phosphorylation (Lee et al. 2004), sumoylation, and nitration (Gong et al. 2005; Reynolds et al. 2006), although the consequences of these modifications are presently unclear. Finally, it has recently been shown that tau can undergo acetylation on multiple lysines (Min et al. 2010; Cohen et al. 2011), including lysine residues (K280/K281) within a MT binding repeat. The acetylation of tau at K280, much like phosphorylation at certain tau residues, impairs the ability of tau to bind MTs and increases its propensity to fibrillize (Cohen et al. 2011). Importantly, tau within NFTs are found to be acetylated at K280 in PSP, CBD, and other tau diseases with inclusions formed by $4-\mathrm{R}$ tau, or in $\mathrm{AD}$ in which NFTs contain a mixture of 4-R and 3-R tau. Similarly, NFT-like inclusions within $\mathrm{Tg}$ mouse models of tauopathy are acetylated at K280. As discussed further below, this suggests that a new therapeutic strategy for $\mathrm{AD}$ and related tauopathies might be the inhibition of tau acetylation.

\section{TAU AS A DRUG TARGET}

The aforementioned studies have provided important information about how tau mutations and posttranslational modification can affect its microtubule binding and assembly into multimeric structures. These findings suggest potential therapeutic strategies to reduce the untoward effects of altered tau in neurodegenerative disease, and these approaches are generally directed to overcoming tau loss-offunction or reducing levels of potentially toxic tau species (Fig. 2). More specifically, there are ongoing research programs within academia and/or industry that are aimed at identifying prototype drug candidates, which will:

- Compensate for a loss of tau stabilization of MTs, given the importance of MTs in axonal transport and proper neuronal function.

- Attenuate tau hyperphosphorylation through the inhibition of key tau kinases, thereby restoring tau interaction with MTs and perhaps reducing tau aggregation.

- Prevent tau-tau interactions and resulting multimerization, thus mitigating the formation of potentially neurotoxic tau species.

- Increase degradation of misfolded or otherwise pathologically altered tau through an enhancement of cellular catabolic pathways, again with the objective of reducing the levels of toxic forms of tau.

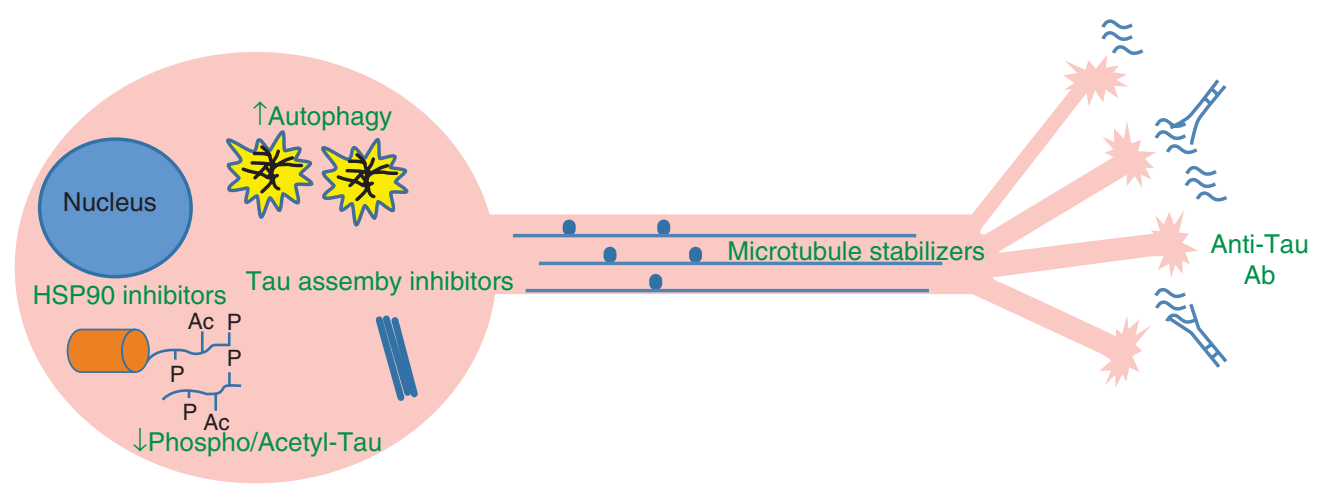

Figure 2. Possible tau-based therapeutic strategies in Alzheimer disease. A loss of tau function might be overcome with microtubule-stabilizing agents or inhibitors of tau hyperphosphorylation and/or acetylation. Potentially toxic tau oligomers or fibrils might be prevented by inhibitors of tau multimeric assembly. Inhibition of HSP90 and the resulting elevation of the chaperones HSP70/HSP40 may increase proteasomal degradation of hyperphosphorylated tau. Misfolded tau multimers might be cleared through enhancement of macroautophagy. Finally, misfolded tau species may be released from cells and internalized by nearby neurons, thereby "seeding" the formation of pathological tau in the recipient cell. If confirmed, this spreading of tau pathology might be inhibited by antibodies that bind misfolded tau in the brain interstitial fluid. 
In addition to the above, there is new emerging evidence that tau pathology may spread in the brain through the release of tau species into the interstitial fluid that can be internalized by nearby neurons, thereby acting as "seeds" to foster the formation of additional pathologic tau (Clavaguera et al. 2009). Further validation of this mechanism of tau transmission would suggest additional therapeutic approaches, including passive immunotherapy strategies whereby tau-directed antibodies might prevent the spread of pathologic tau. In the following sections, we will discuss in detail these various tau-directed strategies for the treatment of $\mathrm{AD}$ and related pathologies, including the challenges associated with each approach.

\section{COMPENSATION FOR TAU LOSS-OF-FUNCTION}

As noted, a possible cause of the neurodegeneration observed in tauopathies is a loss of tau function with resulting MT destabilization. Support for this hypothesis is provided by the observed decrease within the AD brain of the stabilized MT marker, acetyl-tubulin (Hempen and Brion 1996). Likewise, pyramidal neurons in the $\mathrm{AD}$ brain have been reported to have reduced MT density (Cash et al. 2003). Finally, Tg mice that overexpress 3- $\mathrm{R}$ tau display an agedependent formation of intraneuronal tau inclusions in the brainstem, spinal cord, and cortex that is accompanied by a reduction of MT density and deficiencies in fast axonal transport (Ishihara et al. 1999).

These data suggest that compensation for tau loss-of-function with MT-stabilizing drugs might be a therapeutic strategy for the treatment of $\mathrm{AD}$ and related tauopathies. Drugs of this type have been employed for some time in the treatment of cancer, as molecules such as paclitaxel and docetaxol (Saloustros et al. 2008) inhibit cancer cell division through alteration of the mitotic spindle. However, the potent antimitotic properties of these drugs come at the cost of severe side effects, including neutropenia and peripheral neuropathies (Bedard et al. 2010). Thus, it is unlikely that these chemotherapeutic agents could be used safely in
$\mathrm{AD}$ and other tauopathies using current cancer dosing regimens, as long-term dosing would likely be required in these neurodegenerative disorders. However, a complete loss of tau function is unlikely in tauopathies, and thus it may be possible to use doses of MT-stabilizing drugs that are lower than those currently employed in cancer chemotherapy to compensate for loss of tau activity. In fact, important proof-of-principle data have been obtained, which suggest that relatively low doses of a MT-stabilizing compound can improve neuronal deficits that result from tau misfolding. Utilizing the T44 tau Tg mouse model, which shows motor neuron MT deficits and functional impairments (Ishihara et al. 1999), Zhang et al. (2005) showed that weekly administration of 10 or $25 \mathrm{mg} / \mathrm{m}^{2}$ of a paclitaxel formulation for a total of 12 weeks resulted in marked improvements in MT density, fast axonal transport, and motor performance. Furthermore, the drug-treated animals did not show any discernible signs of associated toxicities or side effects. The paclitaxel doses used in this study were much lower than the typical human doses of $135-175 \mathrm{mg} / \mathrm{m}^{2}$, and thus provide hope that small molecule MTstabilizing compounds can be used safely for the treatment of tauopathies.

Although these data provided important validation of the concept of compensating for tau loss-of-function, it is unlikely that paclitaxel will be suitable for the treatment of CNS disorders. The taxanes, including paclitaxel and docetaxel, have poor BBB permeability that is thought to result, at least in part, from these molecules being substrates for the P-glycoprotein (Pgp) transporter that prevents xenobiotics from accumulating in the brain (Sparreboom et al. 1997; Fellner et al. 2002). Improved taxanes have been synthesized that are not Pgp substrates (Cisternino et al. 2003; Ballatore et al. 2007a; Ojima et al. 2008; Metzger-Filho et al. 2009), but recent data from our laboratory suggest that such compounds still have poor brain penetration (Brunden et al. 2011). However, several examples from the epothilone class of MT-stabilizing compounds, some of which have progressed to clinical testing for cancer (Altmann 2005; Beer et al. 2007; Denduluri 
V.M-Y. Lee et al.

et al. 2007), partition readily across the BBB and one of these molecules, epothilone $\mathrm{D}$, has a long-lasting pharmacodynamic effect in the brain (Brunden et al. 2011). Treatment of $\mathrm{Tg}$ mice that express mutant human tau, and which develop NFT-like tau pathology, with low doses of epothilone $\mathrm{D}$ resulted in an improvement of CNS MT density, a reduction of axonal dystrophy, and an improvement of cognitive performance relative to vehicle-treated littermates (Brunden et al. 2010b). Importantly, no side effects were noted in the epothilone D-treated mice in this proof-of-concept prevention study in tau Tg mice, including an absence of neutropenia or signs of peripheral neuropathy. These data suggest that a brain-penetrant MT-stabilizing agent such as epothilone D might be suitable for clinical evaluation in patients with $\mathrm{AD}$ or a related tauopathy.

A potential alternative to brain-penetrant small molecule MT-stabilizing drugs such as the epothilones is the octapeptide, NAP. This peptide is believed to interact with neuronspecific BIII-tubulin (Divinski et al. 2006; Matsuoka et al. 2007), and intranasal administration of NAP to Tg mice that develop both $A \beta$ and tau pathology resulted in a reduction of hyperphosphorylated tau and diminution of A $\beta$ peptide levels. Similarly, a recent study showed that intranasal dosing of NAP to Tg mice expressing mutated tau also led to a reduction of tau phosphorylation (Shiryaev et al. 2009). Although the mechanism(s) by which NAP stabilization of MTs leads to a decrease of tau phosphorylation and $A \beta$ levels is unclear, these data nonetheless provide additional support for a therapeutic strategy of compensating for tau loss-of-function in AD. NAP (davunetide) has progressed to clinical testing, with a Phase IIa trial recently completed in AD patients (see http://www.allontherapeutics.com) and pivotal clinical trials underway.

Although the improvement in MT density observed in tau $\mathrm{Tg}$ mice on treatment with MT-stabilizing molecules suggests a compensation for tau loss-of-function, it is possible that these agents improve neuronal health through additional complementary mechanisms. For example, it has recently been shown that MT stabilization with paclitaxel enhances regeneration after spinal cord injury in rats (Hellal et al. 2011). Injured CNS axons appear to have a collapse of MT integrity that results in the formation of retraction bulbs, and an enhancement of MT stabilization in such cells promotes axon regeneration (Erturk et al. 2007). Thus, it is possible that MT-stabilizing agents such as epothilone $\mathrm{D}$ attenuate axonal retraction/damage that arises from tau-mediated toxicity in tau Tg mouse models. MT-stabilizing compounds might also affect axonal transport by increasing the engagement of motor proteins with MTs. It is known that tau binding to MTs can have an inhibitory effect on kinesin-mediated anterograde axonal transport in cell culture systems in which tau is overexpressed (Stamer et al. 2002; Vershinin et al. 2007; Dixit et al. 2008), although this has not been shown in vivo. Because paclitaxel binding to tubulin has been shown to reduce the amount of tau incorporated into MTs (Kar et al. 2003), it is conceivable that paclitaxel and other MT-stabilizing agents, which share the paclitaxel binding site (such as the epothilones), reduce tau binding to MTs, thereby allowing greater kinesin engagement with MTs and improving anterograde axonal transport. However, this possibility has not yet been investigated in tau Tg mouse models.

\section{INHIBITION OF TAU PHOSPHORYLATION}

Another possible strategy to improve MT stabilization in $\mathrm{AD}$ and other tauopathies is to prevent the phosphorylation that reduces tau interaction with MTs (Alonso et al. 1994, 1996; Wagner et al. 1996; Merrick et al. 1997). Decreasing tau phosphorylation might also reduce levels of unbound tau that are available for the formation of potentially toxic oligomeric and fibrillar structures (Alonso et al. 1996; Necula and Kuret 2004). A therapeutic strategy based on inhibition of tau phosphorylation has practical appeal because protein kinases provide a proven, if extremely difficult, class of drug targets with which the pharmaceutical industry has considerable experience.

Although normal tau is phosphorylated at multiple sites, the extent of phosphorylation 
at these sites is relatively low. However, in $\mathrm{AD}$ brain tau phosphorylation is increased threeto fourfold (Ksiezak-Reding et al. 1992; Kopke et al. 1993; Matsuo et al. 1994), mostly through increased levels of phosphorylation on the tau that is incorporated into neurofibrillary inclusions. There are $\sim 25$ ser and thr residues within tau that appear to be sites of enhanced phosphorylation in AD (Morishima-Kawashima et al. 1995; Hanger et al. 1998), and these are found primarily in the proline-rich domain and the carboxy-terminal region (see Fig. 1), although a few sites also reside within the MT-binding domains (Hanger et al. 2009). A number of candidate kinases have been proposed to play a role in the posttranslational phosphorylation of tau (Mazanetz and Fischer 2007; Gong and Iqbal 2008; Hanger et al. 2009). Among these are kinases that modify ser/thr residues that precede a proline residue, including glycogen synthase kinase 3 (GSK-3) $\alpha$ and $\beta$, cyclin-dependent kinase 5 (CDK5), and mitogen-activated kinase 1 (MAPK1). In addition, nonproline directed kinases such as protein kinase A, p38 and microtubule-affinity regulated kinases (MARK1-4) (Drewes et al. 1997) have been implicated in tau phosphorylation. Of these various kinases, the existing data arguably support GSK-3 $\beta$ and CDK5 as being the best-validated tau kinase targets, and these enzymes will be the focus of further discussion here.

GSK- $3 \alpha$ and/or $\beta$, or more simply GSK-3 because available research tools generally do not discriminate between these closely related isoforms, colocalizes with NFT in the AD brain (Yamaguchi et al. 1996; Imahori and Uchida 1997). Similarly, CDK5 is also found in NFTs (Yamaguchi et al. 1996; Pei et al. 1998; Augustinack et al. 2002). CDK5 requires a regulatory subunit for activity and interacts with p35 and p39, or with their more stable proteolytic products, p25, and p29, respectively. Overexpression of p25 in Tg mice has been reported to result in tau hyperphosphorylation (Ahlijanian et al. 2000; Noble et al. 2003). Similarly, Tg mice expressing GSK-3 $\beta$ display increased tau phosphorylation, as well as learning and memory deficits (Spittaels et al. 2000; Lucas et al. 2001;
Hernandez et al. 2002). Interestingly, there is recent evidence of coordinated regulation of GSK-3 and CDK5, as mice that overexpress the p25 regulatory subunit of CDK5 have decreased GSK-3 activity that has been attributed to phosphorylation of an inhibitory ser $^{9}$ residue on GSK-3 (Wen et al. 2008). Moreover, inhibition of CDK5 resulted in an increase of tau phosphorylation by GSK-3 (Wen et al. 2008). Nonetheless, there are ongoing efforts by a number of industry and academic laboratories to identify inhibitors of both CDK5 and GSK-3.

In the case of GSK-3, these drug discovery activities have been further spurred by the observation that GSK-3 activity may affect $A \beta$ production (Aplin et al. 1997; Phiel et al. 2003; Rockenstein et al. 2007) and by studies in tau $\mathrm{Tg}$ mice in which prototype inhibitors of GSK-3 have been reported to result in a diminution of both tau phosphorylation and intracellular tau inclusions. For example, daily administration of the GSK-3 inhibitor $\mathrm{LiCl}$ for 30 days to JNPL3 tau Tg mice, which overexpress P301L 4R-tau, resulted in the inhibition of GSK-3 activity, reductions of both phosphotau and insoluble tau, and lessening of axonal degeneration (Noble et al. 2005). These authors also showed a similar effect on tau phosphorylation and insolubility using a somewhat selective small molecule GSK-3 inhibitor (Noble et al. 2005). Treatment of another Tg mouse line, which expresses tau harboring three missense mutations, with $\mathrm{LiCl}$ also resulted in a decrement of both tau phosphorylation and tau intracellular inclusions (Perez et al. 2003). Furthermore, treatment of young Tg mice that express 3R-tau with $\mathrm{LiCl}$ for 4 months resulted in a reduction of insoluble tau, although somewhat surprisingly there was not an apparent reduction of the assessed phospho-tau epitopes (Nakashima et al. 2005). Finally, a relatively nonspecific but brain-penetrant kinase inhibitor was shown to decrease total levels of hyperphosphorylated tau (migrating at $64 \mathrm{kDa}$ ) and improve motor function in JNPL3 tau Tg mice, albeit without a reduction of NFTs, thereby suggesting that smaller tau assemblies might have caused neuronal dysfunction (Le Corre et al. 2006). 
V.M-Y. Lee et al.

The various medicinal chemistry approaches that have been employed to develop tau kinase inhibitors have been reviewed elsewhere (Churcher 2006; Mazanetz and Fischer 2007). However, it is worth considering here the challenges associated with this therapeutic strategy. As noted above, a number of candidate kinases have been proposed to phosphorylate tau. However, it is still unclear which of these are important in $\mathrm{AD}$ or even whether the majority of the hyperphosphorylation occurs before or after initial tau assembly. It is possible and perhaps likely that multiple kinases act on tau in the brain, and thus selective inhibition of a single kinase may not prevent the detrimental effects associated with tau hyperphosphorylation. In this regard, it is difficult to develop exquisitely selective kinase inhibitors because most compounds are directed to the ATPbinding site that is common to all kinases. Although a nonselective ser/thr kinase inhibitor may have some advantages in $\mathrm{AD}$ because of the likely involvement of more than one kinase in tau hyperphosphorylation, a lack of selectivity could also lead to an increased likelihood of side effects. Finally, even highly selective inhibition of individual tau kinases implicated in $\mathrm{AD}$ may prove problematic, as these enzymes are known to modify other critical cellular proteins. Such "on-target" dose limiting toxicity is known to impact drug development for GSK-3, which plays an important role in the regulation of glycogen metabolism, cell proliferation, and oncogenesis (Rayasam et al. 2009). Likewise, CDK5 has been suggested to regulate axonal and synaptic function (Dhavan and Tsai 2001).

An alternative approach to decreasing tau hyperphosphorylation would be to increase phosphate removal. The dephosphorylation of tau appears to result primarily from the action of protein phosphatase 2A (PP2A) (Matsuo et al. 1994), and there is evidence that this enzyme is compromised in AD brain (Gong et al. 1995). One potential strategy to increase PP2Amediated dephosphorylation of tau would be to decrease the binding of one or both of the inhibitory proteins that regulate PPA2 activity (Tanimukai et al. 2009).
Another possible alternative strategy to regulating tau phosphorylation has emerged that does not entail kinase inhibition. Tau is also modified through the addition of $\beta-\mathrm{N}$-acetylglucosamine at ser $/$ thr residues (O-GlcNAc), and there is evidence of an inverse relationship between the extent of O-GlcNAc modification and the degree of tau phosphorylation (Lefebvre et al. 2003; Liu et al. 2004). The OGlcNAc modification can be reversed by OGlcNAcase, and a prototype inhibitor of this enzyme caused a decrease of tau phosphorylation in normal rats (Yuzwa et al. 2008). These data suggest that inhibition of O-GlcNAcase may be a potential therapeutic approach for $\mathrm{AD}$ and other tauopathies, although many proteins undergo O-GlcNAc addition and there may therefore be as yet undefined detrimental consequences of sustained inhibition of $\mathrm{O}$ GlcNAcase.

Finally, very recent data indicate that another tau posttranslational modification, acetylation, may impart changes that resemble those observed after phosphorylation (Min et al. 2010; Cohen et al. 2011). In particular, acetylation of lysine residues 280 within a MT binding repeat of tau decreases its ability to induce MT assembly and increases its propensity to fibrillize (Cohen et al. 2011). Tau acetylation has also been suggested to decrease proteasome-mediated degradation of phosphorylated tau (Min et al. 2010). Accordingly, inhibition of tau acetylation in $\mathrm{AD}$ and related 4-R tauopathies could increase tau binding to MTs, reduce tau aggregation, and enhance catabolism of phospho-tau species. The most straightforward approach to attenuating tau acetylation would be inhibition of the appropriate acetyl-transferase(s). However, these enzymes, like protein kinases, have multiple cellular substrates. For example, the p300/CBP acetyl-transferase implicated in tau acetylation (Min et al. 2010; Cohen et al. 2011) has more than 75 described protein substrates (Yang and Seto 2008; Bowers et al. 2010). Thus, it is unclear whether drugs can be developed that will decrease tau acetylation specifically without affecting other substrates that could induce side effects. 


\section{ENHANCEMENT OF TAU DEGRADATION}

The hypothesis that tau oligomers or fibrils are harmful suggests that increased catabolism of pathological tau would be beneficial. Cells are equipped to degrade misfolded proteins by two general mechanisms; via the ubiquitinproteasome system (UPS) and through autophagy (Fig. 2). In the former, proteins that are destined for catabolism are modified on lysine residues through the addition of ubiquitin molecules, with subsequent degradation by the proteasome. Because proteins must gain entry into a "pore" within the proteasome complex to undergo proteolysis, it is unlikely that large oligomeric tau species can be acted on by proteasomes. However, although normal tau is not believed to be degraded by the UPS, this pathway has been implicated in the turnover of phosphorylated tau. The "carboxy terminus of HSP70-interacting protein" (CHIP) appears to regulate tau ubiquitination (Petrucelli et al. 2004; Shimura et al. 2004) and CHIP knockout mice display an accumulation of phospho-tau (Dickey et al. 2006b). CHIP can form a complex with the molecular chaperone HSP70 and target proteins to the proteasome, and increased HSP70 expression in cell culture models leads to a decrease in insoluble phospho-tau and an increase of soluble tau (Dou et al. 2003; Petrucelli et al. 2004). HSP90 is another molecular chaperone that assists in protein refolding, and inhibition of the ATPase function of HSP90 with compounds such as geldanamycin results in an increased expression of HSP70 and HSP40 (Zhang and Burrows 2004). HSP90 inhibition in cell culture leads to an increased degradation of phospho-tau (Dickey et al. 2006a) that appears to result from a change of HSP90 chaperone function such that phospho-tau is targeted to the CHIP/ HSP70 complex, in which it is polyubiquinated and degraded by the proteasome (Dickey et al. 2007). Importantly, HSP90 inhibitors have been shown to reduce the amount of hyperphosphorylated tau in Tg mouse models. Both acute and subchronic dosing of JNPL3 tau Tg mice with the brain-penetrant HSP90 inhibitor PUDZ8 led to a reduction of both soluble and hyperphosphorylated insoluble tau (Luo et al. 2007). Interestingly, PU-DZ8 treatment also caused a reduction of $\mathrm{p} 35$, the cofactor required for CDK5 activity. Thus, HSP90 inhibition may affect phosphorylated tau levels both through increased proteasomal degradation of tau and reduced CDK5-mediated tau phosphorylation. In another study, a 7-day administration of the HSP90 inhibitor EC102 to Tg mice that express all six isoforms of normal human tau and which develop tau inclusions, resulted in a reduction of phospho-tau species (Dickey et al. 2007).

As with all therapeutic strategies, the possible benefits of HSP90 inhibition will have to be weighed against potential safety risks. A priori, it would seem that prolonged HSP90 inhibition would be problematic, as this will lead to the degradation of other Hsp90 client proteins in addition to tau. Moreover, genetic knockout of HSP90 in mice is lethal. However, there appears to be some selectivity of HSP90 inhibitors for HSP90 found within cancer cells as opposed to normal cells (Solit and Chiosis 2008; Mahalingam et al. 2009). Although the reason for this selectivity is not fully understood, several hypotheses have been proposed (Chiosis and Neckers 2006; Solit and Chiosis 2008). These include the possibility of a preferential binding of inhibitors to HSP90 that is bound to multimeric chaperone complexes that are elevated in cancer cells (Kamal et al. 2003), or that HSP90 levels may be limiting in cancer cells because of an increased burden of misfolded proteins. Regardless of the explanation, it remains to be shown whether neurons harboring excessive hyperphosphorylated tau are also selectively affected by HSP90 inhibitors, although it appears that HSP90 inhibitors bind to cortical homogenates from $\mathrm{AD}$ brain with greater affinity than to those from control brain (Dickey et al. 2007).

As noted, misfolded and/or hyperphosphorylated tau that assembles into larger oligomers or fibrils is unlikely to be degraded by the UPS because of their exclusion from the proteasome pore. However, there is evidence that larger protein aggregates, including tau multimers, can be cleared through autophagy. 
V.M-Y. Lee et al.

Multiple forms of autophagy have been described (Nixon 2006; Williams et al. 2006), but the degradation of large protein aggregates and defective cellular organelles is believed to occur via macroautophagy, whereby an autophagasome encapsulates the material to be degraded and subsequently fuses with a lysosome. Macroautophagy can be induced with the drug rapamycin, and treatment of flies expressing wild-type or mutant human tau with rapamycin led to a diminution of insoluble tau (Berger et al. 2006). Conversely, perturbation of lysosome function or inhibition of autophagy in neuroblastoma cells expressing human tau resulted in slower tau clearance (Hamano et al. 2008). More recent work has implicated the autophagy-lysosomal system in tau fragmentation and the clearance of tau aggregates (Wang et al. 2009). Thus, although there are still relatively few reports on the role of autophagy in the degradation of misfolded tau, it is possible that up-regulation of this cellular process might be beneficial in reducing pathological tau species. However, it is not entirely clear that an induction of autophagy will be beneficial in AD and other tauopathies, as it has been suggested that the autophagic deficits, which have been observed in $\mathrm{AD}$ brain result from impaired clearance of autophagic vesicles and not faulty initiation of autophagy (Boland et al. 2008).

If an up-regulation of autophagy is found to be an appropriate strategy for $\mathrm{AD}$, it should be noted that the most characterized inducer of autophagy, rapamycin, alters the mTOR signaling pathway and has a variety of other biological effects, including immunosuppression (Delgoffe and Powell 2009). Moreover, there is evidence that rapamycin suppresses tau translation, which appears to be regulated by the mTOR effector 70-kDA ribosomal protein S6 kinase (Morita and Sobue 2009). Thus, although chronic treatment of WT mice with rapamycin extended their lifespan and reduced aging related diseases (Harrison et al. 2009; Miller et al. 2011), the potential complications of prolonged alteration of the mTOR signal transduction suggest that alternative autophagy enhancers will be required for the treatment of neurodegenerative disease. In this regard, $\mathrm{LiCl}$ has been suggested to induce autophagy through its inhibition of inositol monophosphatase (Sarkar et al. 2005) and, in fact, it is possible that the reduction in phosphorylated tau levels (Noble et al. 2005) and the reduction of tau lesions (Nakashima et al. 2005) observed on $\mathrm{LiCl}$ treatment discussed above were due both to effects both on GSK3 and autophagy.

In addition to up-regulating intracellular tau degradation, another potential approach to lowering misfolded tau in $\mathrm{AD}$ brain is via active or passive immunization (Fig. 2). A similar strategy is presently being pursued to lower senile plaque burden, as several active and passive $A \beta$ immunization clinical trials have been completed or are ongoing (Orgogozo et al. 2003; Rinne et al. 2010; Wilcock 2010). Multiple hypotheses have been proposed to explain how $\mathrm{A} \beta$ antibodies could lead to plaque reductions. For example, it is possible that a low level of $\mathrm{A} \beta$ antibody enters the brain and binds to plaques, thereby invoking complement-mediated microglial clearance. Alternatively, a peripheral sink mechanism may exist whereby the formation of $A \beta$-antibody complexes in blood lowers free $A \beta$ levels, altering the brain-blood $A \beta$ equilibrium such that $A \beta$ moves from the brain into the blood.

Regardless of how $A \beta$ antibodies might reduce plaques, these data beg the question of whether tau immunization might reduce misfolded tau in the AD brain. It is important to point out that, unlike senile plaques, NFTs and tau neuropil threads are generally intracellular. Thus, tau inclusions would not likely be accessible at sufficient levels to extracellular antibody that enters the brain parenchyma from blood. Although these fundamental concerns suggest that tau immunization may not be a practical therapeutic approach for $\mathrm{AD}$, recent data provide reason for cautious optimism. In particular, an interesting and provocative study (Clavaguera et al. 2009) showed that injection of brain-derived pathological tau from one tau Tg mouse line into the brains of another tau Tg mouse line that does not normally form intraneuronal inclusions led to the formation of pathological tau deposits in the 
recipient mice. These results suggest that misfolded tau that is released into the brain interstitial fluid, perhaps from injured or dying neurons, might be internalized by nearby cells to "seed" further tau misfolding and accumulation. This hypothesis is further bolstered by studies, which indicate that aggregated tau can be transferred between cells in culture (Frost et al. 2009). If further confirmed, this mechanism of tau transmission may provide an explanation for the observed stereotypical spreading of tau pathology in AD (Braak et al. 1993), and suggests that an antitau antibody which recognizes the "seeding" tau species might prevent the transmission and further progression of tau pathology. In this regard, there has been a report of tau immunotherapy in which JNPL3 tau Tg mice were vaccinated with a phospho-tau peptide (Asuni et al. 2007). Antiantigen antibodies were generated by the mice, and there was a reduction of pathological tau as assessed by immunohistochemistry. Whether this amelioration of tau pathology resulted from a slowing of tau transmission or through another mechanism is unknown, but additional studies of tau immunization in Tg models of AD are warranted. However, it should be noted that vaccination of wild-type mice with recombinant human tau led to the induction of NFT-like structures, axonal damage, and gliosis (Rosenmann et al. 2006). Thus, certain tau immunogens may be detrimental and perhaps a passive immunization approach using antibodies directed to the misfolded tau species responsible for cell-to-cell transmission would have fewer side effects.

Finally, it should be noted that another therapeutic strategy that has recently been suggested for $\mathrm{AD}$ is to lower overall tau levels (i.e., not just hyperphosphorylated or misfolded tau). Initial support for this concept was provided by data demonstrating that hAPP (PDAPP) Tg mice, which develop $A \beta$ plaques like those seen in $A D$, show reduced behavioral deficits when endogenous tau levels were lowered by crossing the hAPP mice with tau ${ }^{-1-}$ mice (Roberson et al. 2007). This behavioral improvement was not caused by changes in $A \beta$ or senile plaque levels in the $\mathrm{hAPP} / \mathrm{tau}^{-/-}$mice relative to
$\mathrm{hAPP} / \mathrm{tau}^{+/+}$counterparts. Interestingly, the reduction of tau also led to greater resistance to excitotoxic insults (Roberson et al. 2007). This observation may relate to recent data indicating that tau has a dendritic function in the postsynaptic targeting of the kinase Fyn (Ittner et al. 2010). Fyn-mediated phosphorylation of the NR2b subunit of the NMDA receptor strengthens its interaction with the postsynaptic protein, PSD95. Tau-deficient mice were shown to have reduced susceptibility to excitotoxic seizures because of impaired NMDA-PSD95 interaction (Ittner et al. 2010). Moreover, hAPP (APP23) $/ \mathrm{tau}^{-/-}$mice showed improved cognitive performance relative to tau-expressing hAPP controls, presumably because of a reduction of $A \beta$-mediated excitotoxicity that was thought to be dependent on the presence of tau (Ittner et al. 2010).

Although these data suggest that there may be value in lowering total tau levels in $\mathrm{AD}$, this perspective is not universally embraced, and caution should be exercised in the interpretation of these results. First, there is another recent report, which suggests that a loss of tau is detrimental and enhances degeneration in a another hAPP $\left(\mathrm{A}_{\mathrm{sw}}\right) \mathrm{Tg}$ mouse model (Dawson et al. 2010). In addition, the absence of a profound

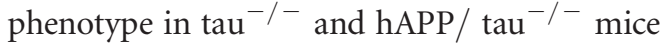
might suggest that a loss of tau is well tolerated and does not greatly affect MT function. However, these mice do develop some neurological impairments with age, including cognitive and motor deficits (Harada et al. 1994; Ikegami et al. 2000). In addition, there may well be compensatory changes during development that offset the loss of tau in these knockout mice. In this regard, it has been reported that $\mathrm{tau}^{-/-}$have increased expression of MAP1a (Harada et al. 1994). Although a therapeutic strategy based on the lowering of total tau levels merits further study, a "Goldilocks-like" balance may be needed whereby tau concentrations are decreased enough to reduce Fyn targeting to dendrites but not so much as to compromise tau-mediated MT stabilization. In this regard, the combination of a tau-lowering agent and a MT-stabilizing compound might address both $\mathrm{A} \beta$ - and tau-mediated toxicities in $\mathrm{AD}$. 
V.M-Y. Lee et al.

\section{INHIBITION OF TAU FIBRILLIZATION}

The hypothesis that tau fibril formation may be spread by the internalization of misfolded extracellular tau seeds will require further study. However, it is generally accepted that tau fibrils are formed from a nucleation-elongation process in which a misfolded tau nucleating structure is formed that then promotes the further assembly of normal tau protein into oligomers and ultimately fibrils (Margittai and Langen 2004; Congdon et al. 2008). Thus, one conceptually straightforward strategy to prevent the formation of potentially harmful tau oligomers and/or fibrils would be to identify molecules that block the formation of tau nucleating structures and/or the elongation of nascent protofibrils (Fig. 3). Although simple in theory, this therapeutic approach is challenging from a drug development perspective because of the difficulty of disrupting protein-protein interactions that involve large surface areas. The search for inhibitors of tau assembly has been greatly aided by the discovery that bona fide fibrils with verisimilitude to those found in $\mathrm{AD}$ brain can be formed in vitro from isolated recombinant tau (Wille et al. 1992), with this assembly facilitated significantly by coincubation with anionic cofactors such as heparin or arachidonic acid (Goedert et al. 1996; Wilson and Binder 1997). This has led to efforts in several laboratories to identify inhibitors of tau fibril formation, and a number of molecules with differing chemical scaffolds have been described and discussed in several recent reviews (Brunden et al. 2009, 2010a; Ballatore et al. 2010b; Bulic et al. 2010). The chemical or biological properties of many of these compounds may preclude their use in animals or humans, although some may have potential for further development.

Interestingly, one of the first described tau fibrillization inhibitors has progressed to clinical testing in $\mathrm{AD}$ patients. Methylene blue was shown to block tau-tau interactions and alter tau fibril structure in 1996 (Wischik et al. 1996), and a Phase II AD clinical trial has recently been completed with this compound (trade name of Rember ${ }^{\mathrm{TM}}$ ) (Staff et al. 2008). The clinical data suggest that the drug-treatment group had reduced cognitive decline relative to the placebo group, although interpretation of the data was complicated by problems with the formulation of the highest dose group that led to lower than expected exposures of the drug. These preliminary clinical data are encouraging, and further confirmation of efficacy in a pivotal Phase III trial could provide important validation of the use of tau fibrillization inhibitors for the treatment of AD. It should be noted that methylene blue is known to be a highly promiscuous molecule that can affect multiple protein targets (Gillman 2010; Oz et al. 2010). Therefore, effects in AD patients,

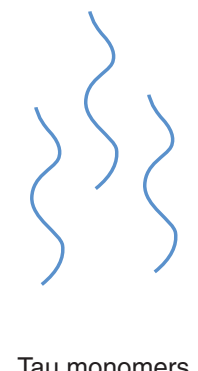

Tau monomers
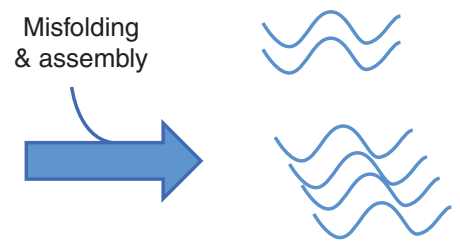

Nucleating structures

(Dimers and/or oligomers)

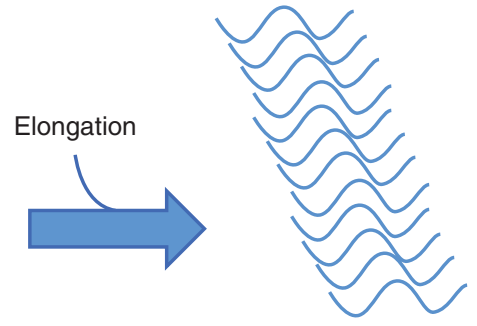

Tau fibrils

Figure 3. The assembly of tau into multimers and fibrils. Tau is normally unstructured in solution, and in axons the majority of tau is typically associated with MTs. In AD, tau can become misfolded and assemble into multimeric structures. Certain of these multimers can serve as nucleating structures to which additional tau can be added to yield classical amyloid-type fibrils. 
even if confirmed in a Phase III study, may not be solely attributable to prevention of tau fibrillization.

To our knowledge, no other inhibitors of tau fibril assembly have progressed to efficacy testing in animal models of $\mathrm{AD}$ or tauopathy. Several inhibitors of tau fibrillization have been shown to inhibit tau inclusion formation in a cell-based model (Pickhardt et al. 2005, 2007; Khlistunova et al. 2006; Bulic et al. 2007), and one or more of these compounds may be suitable for testing in animals if they have appropriate pharmacokinetic properties and can cross the BBB. In this regard, example molecules from the aminothienopyridazine (ATPZ) class of tau fibrillization inhibitors have been identified that are absorbed orally in mice and which show good plasma half-lives along with equilibration across the BBB (Ballatore et al. 2010a). Thus, it is likely that one or more novel tau fibrillization inhibitors will be examined in a mouse model of tauopathy in the near future.

In most reports, the concentrations of compound required to inhibit tau fibrillization were nearly equimolar to the tau concentration used in the in vitro assays (Brunden et al. 2009, 2010a). This suggests that most of the described tau fibrillization inhibitors either have a relatively low affinity for tau, or that they form complexes with misfolded monomers or small multimers of tau to prevent fibrillization. It will therefore be important to show that the fibrillization inhibitors do not alter normal tau function. For example, the ATPZ class of tau fibril assembly inhibitors do not appear to affect the ability of tau to promote MT stabilization (Crowe et al. 2009; Ballatore et al. 2010a). A mechanism based on compound interaction with monomeric tau also raises the issue of whether sufficient brain drug levels can be achieved to bind the majority of tau monomers within neurons. In this regard, it has been estimated that under normal circumstances $>99 \%$ of tau is bound to MTs (Congdon et al. 2008). Although the amount of tau bound to MTs is presumably reduced in tauopathies, even a 10 -fold increase in free tau would still result in a sub- $\mu \mathrm{M}$ concentration of tau monomers if a total intraneuronal cytoplasmic tau level of $\sim 1 \mu \mathrm{M}$ is assumed (Drubin et al. 1985). Thus, it should be feasible to attain effective brain concentrations of brain-penetrant tau fibril inhibitors. Moreover, tau aggregation inhibitors might also be expected to interfere with the extracellular transmission of aggregated tau nuclei, if this mechanism of pathology spreading plays a significant role, which would further increase the likely efficacy of stoichiometric inhibitors at feasible exposure levels.

\section{UNIQUE CHALLENGES OF TAU-DIRECTED DRUG DISCOVERY AND DEVELOPMENT}

Many of the complexities associated with taudirected drug discovery approaches were mentioned in the previous sections. However, certain aspects of these challenges merit further discussion, particularly as they compare to therapeutic strategies focused on reducing $A \beta$ levels in $\mathrm{AD}$. As discussed in other articles within this volume, there have been significant advances in the development of inhibitors of the $\beta$ - and $\gamma$-secretase enzymes that are responsible for the release of A $\beta$ from APP. The pharmaceutical industry has considerable experience in developing enzyme inhibitors, and thus the APP-processing secretases are viewed as highly "druggable" targets. In contrast, the tau-based strategies discussed here are not focused on classical pharmaceutical drug targets, with the debatable exceptions of the tau kinases and HSP90. In fact, even the development of tau kinase and HSP90 inhibitors is rendered more difficult by the uncertainty of which kinase(s) are responsible for tau hyperphosphorylation, the challenges of developing kinase inhibitors with sufficient selectivity and the very real possibility of on-target toxicity linked to the critical functional role of the known tau kinases and Hsp90. The totality of these challenges to tau drug discovery has resulted in relatively modest industry efforts in this research area to date, although there are signs of increased interest in tau-directed therapeutic approaches.

Because of the complexities of tau drug discovery strategies, the academic community has an important role to play in validating 
V.M-Y. Lee et al.

these therapeutic methods. This is particularly true for the more unconventional pharmaceutical tactics, such as inhibition of tau multimer assembly, increasing tau degradation through up-regulation of autophagy, blocking tau spread in the brain with antibodies, or compensating for tau loss-of-function with MT stabilizing compounds. In each of these cases, the development of prototype reagents of sufficient quality to test the hypothesis and subsequent demonstration of proof-of-principle efficacy in established Tg mouse models of tauopathy will be critical to generating future industry investment in these therapeutic strategies. It is important that the design of these studies and the Tg models used be considered carefully. Previously published tau-based drug studies in $\mathrm{Tg}$ models have often suffered from underpowered group sizes, as well as a lack of information on drug exposure levels and target engagement. Moreover, there is a clear need for agreement on what constitutes robust efficacy endpoints linked to tau pathogenesis and associated neurodegeneration.

Although there are clear challenges to taubased drug discovery, there may also be advantages relative to $A \beta$-targeted approaches. Emerging data suggest that $A \beta$ deposition into senile plaques could occur years before the onset of cognitive deficits (Jack et al. 2010). Thus, it is possible that a drug designed to reduce $A \beta$ levels and senile plaques would need to be administered well before the onset of AD clinical symptoms to be effective in slowing or preventing disease progression. Advancements in PET/MRI brain imaging and other biomarkers may eventually allow for the identification of nonsymptomatic individuals at risk for AD. However, demonstration of efficacy with an $A \beta$-directed drug in such a population may require multiple years of dosing unless a highly validated surrogate marker is identified and approved by regulatory agencies. In contrast, the development of tau inclusions appears to be more proximal to the onset of memory deficits (Jack et al. 2010). Thus, there may be a greater chance of demonstrating efficacy with a tau-directed agent in patients with MCI and early $A D$ than with an $A \beta$-directed drug.
In conclusion, there are compelling reasons to attempt to identify drug candidates that can reduce the extent of tau-induced pathology in $\mathrm{AD}$ and related tauopathies. Although this area of drug discovery research is not as advanced as that directed to reducing $A \beta$ and senile plaque levels in $\mathrm{AD}$ there is growing interest in taufocused approaches as the central role of this pathology in the disease becomes more widely appreciated and the relevant research tools continue to improve.

\section{ACKNOWLEDGMENTS}

We thank our colleagues and collaborators for their contributions to the work summarized here, which has been supported by grants from the NIH (P01 AG09215, P30 AG10124, P01 AG11542, P01 AG14382, P01 AG14449, P01 AG17586, PO1 AG19724, P01 NS-044233, UO1 AG24904), the Nathan Bilger Alzheimer Initiative, and the Marian S. Ware Alzheimer Program. Finally, we are indebted to our patients and their families whose commitment to research has made our work possible.

\section{REFERENCES}

Ahlijanian MK, Barrezueta NX, Williams RD, Jakowski A, Kowsz KP, McCarthy S, Coskran T, Carlo A, Seymour PA, Burkhardt JE, et al. 2000. Hyperphosphorylated tan and neurofilament and cytoskeletal disruptions in mice overexpressing human p25, an activator of cdk5. Proc Natl Acad Sci 97: 2910-2915.

Alonso AD, Zaidi T, Grundke-Iqbal I, Iqbal K. 1994. Role of abnormally phosphorylated tan in the breakdown of microtubules in Alzheimer-disease. Proc Natl Acad Sci 91: $5562-5566$.

Alonso AD, Grundke-Iqbal I, Iqbal K. 1996. Alzheimer's disease hyperphosphorylated tau sequesters normal tau into tangles of filaments and disassembles microtubules. Nat Med 2: 783-787.

Altmann KH. 2005. Recent developments in the chemical biology of epothilones. Curr Pharm Des 11: 1595-1613.

Andreadis A, Brown WM, Kosik KS. 1992. Structure and novel exons of the human-tau gene. Biochemistry 31: 10626-10633.

Aplin AE, Jacobsen JS, Anderton BH, Gallo JM. 1997. Effect of increased glycogen synthase kinase-3 activity upon the maturation of the amyloid precursor protein in transfected cells. Neuroreport 8: 639-643.

Arriagada PV, Growdon JH, Hedleywhyte ET, Hyman BT. 1992. Neurofibrillary tangles but not senile plaques 
parallel duration and severity of Alzheimers disease. Neurology 42: 631-639.

Asuni AA, Boutajangout A, Quartermain D, Sigurdsson EM. 2007. Immunotherapy targeting pathological tau conformers in a tangle mouse model reduces brain pathology with associated functional improvements. $J$ Neurosci 27: 9115-9129.

Augustinack JC, Sanders JL, Tsai LH, Hyman BT. 2002. Colocalization and fluorescence resonance energy transfer between cdk5 and AT8 suggests a close association in pre-neurofibrillary tangles and neurofibrillary tangles. $J$ Neuropathol Exp Neurol 61: 557-564.

Avila J. 2006. Tau phosphorylation and aggregation in Alzheimer's disease pathology. FEBS Lett 580: 2922-2927.

Avila J, Santa-Maria I, Perez M, Hernandez F, Moreno F. 2006. Tau phosphorylation, aggregation, and cell toxicity. J Biomed Biotech 2006: 1-5.

Ballatore C, Hyde E, Deiches RF, Lee VMY, Trojanowski JQ, Huryn D, Smith AB. 2007a. Paclitaxel C-10 carbamates: Potential candidates for the treatment of neurodegenerative tauopathies. Bioorg Med Chem Lett 17: 3642-3646.

Ballatore C, Lee VMY, Trojanowski JQ. 2007b. Tau-mediated neurodegeneration in Alzheimer's disease and related disorders. Nat Rev Neurosci 8: 663-672.

Ballatore C, Brunden KR, Piscitelli F, James MJ, Crowe A, Yao Y, Hyde E, Trojanowsi JQ, Lee VM-Y, Smith AB III. 2010a. Discovery of brain-penetrant, orally bioavailable aminothienopyridazine inhibitors of tau aggregation. $J$ Med Chem 53: 3739-3747.

Ballatore C, Brunden KR, Trojanowski JQ, Lee VM-Y, Smith AB III, Huryn D. 2010b. Modulation of protein-protein interactions as a therpeutic strategy for the treatment of neurodegenerative tauopathies. Curr Topics Med Chem 11: $317-330$.

Barghorn S, Mandelkow E. 2002. Toward a unified scheme for the aggregation of tau into Alzheimer paired helical filaments. Biochemistry 41: 14885-14896.

Barghorn S, Zheng-Fischhofer Q, Ackmann M, Biernat J, von Bergen M, Mandelkow EM, Mandelkow E. 2000. Structure, microtubule interactions, and paired helical filament aggregation by tau mutants of frontotemporal dementias. Biochemistry 39: 11714-11721.

Bedard PL, Di Leo A, Piccart-Gebhart MJ. 2010. Taxanes: Optimizing adjuvant chemotherapy for early-stage breast cancer. Nat Rev Clin Oncol 7: 22-36.

Beer TM, Higano CS, Saleh M, Dreicer R, Hudes G, Picus J, Rarick M, Fehrenbacher L, Hannah AL. 2007. Phase II study of KOS-862 in patients with metastatic androgen independent prostate cancer previously treated with docetaxel. Invest New Drugs 25: 565-570.

Berger Z, Ravikumar B, Menzies FM, Oroz LG, Underwood BR, Pangalos MN, Schmitt I, Wullner U, Evert BO, O'Kane CJ, et al. 2006. Rapamycin alleviates toxicity of different aggregate-prone proteins. Hum Mol Genet 15: 433-442.

Boland B, Kumar A, Lee S, Platt FM, Wegiel J, Yu WH, Nixon RA. 2008. Autophagy induction and autophagosome clearance in neurons: Relationship to autophagic pathology in Alzheimer's disease. J Neurosci 28: 6926-6937.

Bowers EM, Yan G, Mukherjee C, Orry A, Wang L, Holbert MA, Crump NT, Hazzalin CA, Liszczak G, Yuan H, et al.
2010. Virtual ligand screening of the p300/CBP histone acetyltransferase: Identification of a selective small molecule inhibitor. Chem Biol 17: 471-482.

Braak H, Braak E. 1991. Neuropathological staging of Alzheimer-related changes. Acta Neuropathol 82: 239-259.

Braak H, Braak E, Bohl J. 1993. Staging of Alzheimer-related cortical destruction. Eur Neurol 33: 403-408.

Bramblett GT, Goedert M, Jakes R, Merrick SE, Trojanowski JQ, Lee VMY. 1993. Abnormal tau-phosphorylation at Ser(396) in Alzheimers-disease recapitulates development and contributes to reduced microtubule-binding. Neuron 10: 1089-1099.

Brunden KR, Trojanowski JQ, Lee VMY. 2009. Advances in tau-focused drug discovery for Alzheimer's disease and related tauopathies. Nat Rev Drug Discov 8: 783-793.

Brunden KR, Ballatore C, Crowe A, Smith AB III, Lee VM-Y, Trojanowski JQ. 2010a. Tau-directed drug discovery for Alzheimer's disease and related tauopathies: A focus on tau assembly inhibitors. Exp Neurol 223: 304-310.

Brunden KR, Zhang B, Carroll J, Yao Y, Potuzak JS, Hogan A-ML, Iba M, James MJ, Xie SX, Ballatore C, et al. 2010b. Epothilone D improves microtubule denstiry, axonal integrity and cognition in a transgenic mouse model of tauopathy. J Neurosci 30: 13861-13866.

Brunden KR, Yao Y, Potuzak JS, Ferrar NI, Ballatore C, James MJ, Hogan AL, Trojanowski JQ, Smith AB3, Lee VMY. 2011. The characterization of microtubule-stabilizing drugs as possible therapeutic agents for Alzheimer's disease and related tauopathies. Pharmacol Res 63:341-351.

Buee L, Bussiere T, Buee-Scherrer V, Delacourte A, Hof PR. 2000. Tau protein isoforms, phosphorylation and role in neurodegenerative disorders. Brain Res Rev 33: 95-130.

Bulic B, Pickhardt M, Khlistunova I, Biernat J, Mandelkow EM, Mandelkow E, Waldmann H. 2007. Rhodaninebased tau aggregation inhibitors in cell models of tauopathy. Angewandte Chem-International Edition 46: 9215-9219.

Bulic B, Pickhardt M, Mandelkow EM, Mandelkow E. 2010. Tau protein and tau aggregation inhibitors. Neuropharmacology 59: 276-289.

Cash AD, Aliev G, Siedlak SL, Nunomura A, Fujioka H, Zhu XW, Raina AK, Vinters HV, Tabaton M, Johnson AB, et al 2003. Microtubule reduction in Alzheimer's disease and aging is independent of tau filament formation. Am J Pathol 162: 1623-1627.

Chiosis G, Neckers L. 2006. Tumor selectivity of Hsp90 inhibitors: The explanation remains elusive. ACS Chem Biol 1: 279-284.

Churcher I. 2006. Tau therapeutic strategies for the treatment of Alzheimer's disease. Curr Topics Med Chem 6: 579-595.

Cisternino S, Bourasset F, Archimbaud Y, Semiond D, Sanderink G, Scherrmann JM. 2003. Nonlinear accumulation in the brain of the new taxoid TXD258 following saturation of P-glycoprotein at the blood-brain barrier in mice and rats. Br J Pharmacol 138: 1367-1375.

Clavaguera F, Bolmont T, Crowther RA, Abramowski D, Frank S, Probst A, Fraser G, Stalder AK, Beibel M, Staufenbiel M, et al. 2009. Transmission and spreading of 
V.M-Y. Lee et al.

tauopathy in transgenic mouse brain. Nature Cell Biol 11: 909-913.

Cohen TJ, Guo J, Hurtado DE, Kwong LK, Mills IP, Trojanowski JQ, Lee VMY. 2011. Tau acetylation inhibits its function and accelerates aggregation. Nature Comm 2: 252 .

Congdon EE, Kim S, Bonchak J, Songrug T, Matzavinos A, Kuret J. 2008. Nucleation-dependent tau filament formation-The importance of dimerization and an estimation of elementary rate constants. J Biol Chem 283: 13806-13816.

Crowe A, Huang W, Ballatore C, Johnson R, Hogan A, Huang R, Wichtermann J, McCoy J, Huryn D, Auld D, et al. 2009. The identification of aminothienopyridazine inhibitors of tau assembly by quantitative high-throughput screening. Biochemistry 48: 7732-7745.

Dawson HN, Cantillana V, Jansen M, Wang H, Vitek MP, Wilcock DM, Lynch JR, Laskowitz DT. 2010. Loss of tau elicits axonal degeneration in a mouse model of Alzheimer's Disease. Neuroscience 169: 516-531.

Dayanandan R, Van Slegtenhorst M, Mack TGA, Ko L, Yen SH, Leroy K, Brion JP, Anderton BH, Hutton M, Lovestone S. 1999. Mutations in tau reduce its microtubule binding properties in intact cells and affect its phosphorylation. FEBS Lett 446: 228-232.

Delgoffe GM, Powell JD. 2009. mTOR: Taking cues from the immune microenvironment. Immunology 127: 459-465.

Denduluri N, Low JA, Lee JJ, Berman AW, Walshe JM, Vatas U, Chow CK, Steinberg SM, Yang SX, Swain SM. 2007. Phase II trial of ixabepilone, an epothilone B analog, in patients with metastatic breast cancer previously untreated with taxanes. J Clin Oncol 25: 3421-3427.

Dhavan R, Tsai LH. 2001. A decade of CDK5. Nature Rev Molec Cell Biol 2: 749-759.

Dickey CA, Dunmore J, Lu BW, Wang JW, Lee WC, Kamal A, Burrows F, Eckman C, Hutton M, Petrucelli L. 2006a. HSP induction mediates selective clearance of tau phosphorylated at proline-directed Ser/Thr sites but not KXGS (MARK) sites. FASEB J 20: 753-755.

Dickey CA, Yue M, Lin WL, Dickson DW, Dunmore JH, Lee WC, Zehr C, West G, Cao S, Clark AMK, et al. 2006b. Deletion of the ubiquitin ligase CHIP leads to the accumulation, but not the aggregation, of both endogenous phospho- and caspase-3-cleaved tau species. J Neurosci 26: 6985-6996.

Dickey CA, Kamal A, Lundgren K, Klosak N, Bailey RM, Dunmore J, Ash P, Shoraka S, Zlatkovic J, Eckman CB, et al. 2007. The high-affinity HSP90-CHIP complex recognizes and selectively degrades phosphorylated tau client proteins. J Clin Invest 117: 648-658.

Divinski I, Holtser-Cochav M, Vulih-Schultzman I, Steingart RA, Gozes I. 2006. Peptide neuroprotection through specific interaction with brain tubulin. J Neurochem 98: 973-984.

Dixit R, Ross JL, Goldman YE, Holzbaur ELF. 2008. Differential regulation of dynein and kinesin motor proteins by tau. Science 319: 1086-1089.

Dou F, Netzer WJ, Tanemura K, Li F, Hartl FU, Takashima A, Gouras GK, Greengard P, Xu HX. 2003. Chaperones increase association of tau protein with microtubules. Proc Natl Acad Sci 100: 721-726.
Drechsel DN, Hyman AA, Cobb MH, Kirschner MW. 1992. Modulation of the dynamic instability of tubulin assembly by the microtubule-associated protein tau. Mol Biol Cell 3: 1141-1154.

Drewes G, Ebneth A, Preuss U, Mandelkow EM, Mandelkow E. 1997. MARK, a novel family of protein kinases that phosphorylate microtubule-associated proteins and trigger microtubule disruption. Cell 89: 297-308.

Drubin DG, Feinstein SC, Shooter EM, Kirschner MW 1985. Nerve growth-factor induced Neurite Outgrowth in Pc12 cells involves the coordinate induction of microtubule assembly and assembly-promoting factors. J Cell Biol 101: 1799-1807.

Erturk A, Hellal F, Enes J, Bradke F. 2007. Disorganized microtubules underlie the formation of retraction bulbs and the failure of axonal regeneration. $J$ Neurosci 27: 9169-9180.

Fellner S, Bauer B, Miller DS, Schaffrik M, Fankhanel M, Spruss T, Bernhardt G, Graeff C, Farber L, Gschaidmeier $\mathrm{H}$, et al. 2002. Transport of paclitaxel (Taxol) across the blood-brain barrier in vitro and in vivo. J Clin Invest 110: 1309-1318.

Frost B, Jacks RL, Diamond MI. 2009. Propagation of tau misfolding from the outside to the inside of a cell. $J$ Biol Chem 284: 12845-12852.

Gillman PK. 2011. CNS toxicity involving methylene blue: The exempler for understanding and predicting drug interactions that precipitate serotonin toxicity. J Psychopharmacol 25: 429-436.

Glenner GG, Wong CW. 1984. Alzheimers disease-initial report of the purification and characterization of a novel cerebrovascular amyloid protein. Biochem Biophys Res Commun 120: 885-890.

Goedert M, Jakes R. 2005. Mutations causing neurodegenerative tauopathies. Biochim Biophys Acta-Molecular Basis of Disease 1739: 240-250.

Goedert M, Spillantini MG, Jakes R, Rutherford D, Crowther RA. 1989. Multiple isoforms of human microtubule-associated protein-tau-sequences and localization in neurofibrillary tangles of Alzheimers-disease. Neuron 3: 519-526.

Goedert M, Jakes R, Spillantini MG, Hasegawa M, Smith MJ, Crowther RA. 1996. Assembly of microtubuleassociated protein tau into Alzheimer-like filaments induced by sulphated glycosaminoglycans. Nature 383: 550-553.

Gomez-Isla T, Hollister R, West H, Mui S, Growdon JH, Petersen RC, Parisi JE, Hyman BT. 1997. Neuronal loss correlates with but exceeds neurofibrillary tangles in Alzheimer's disease. Ann Neurol 41: 17-24.

Gong CX, Iqbal K. 2008. Hyperphosphorylation of microtubule-associated protein tau: A promising therapeutic target for Alzheimer disease. Curr Med Chem 15: 2321-2328.

Gong CX, Shaikh S, Wang JZ, Zaidi T, Grundke-Iqbal I, Iqbal K. 1995. Phosphatase-activity toward abnormally phosphorylated-tau-decrease in Alzheimer-disease brain. J Neurochem 65: 732-738.

Gong CX, Liu F, Grundke-Iqbal I, Iqbal K. 2005. Posttranslational modifications of tau protein in Alzheimer's disease. J Neural Transm 112: 813-838. 
Gustke N, Trinczek B, Biernat J, Mandelkow EM, Mandelkow E. 1994. Domains of tau-protein and interactions with microtubules. Biochemistry 33: 9511-9522.

Hamano T, Gendron TF, Causevic E, Yen SH, Lin WL, Isidoro C, DeTure M, Ko LW. 2008. Autophagic-lysosomal perturbation enhances tau aggregation in transfectants with induced wild-type tau expression. Eur J Neurosci 27: 1119-1130.

Hanger DP, Betts JC, Loviny TLF, Blackstock WP, Anderton BH. 1998. New phosphorylation sites identified in hyperphosphorylated tau (paired helical filament-tau) from Alzheimer's disease brain using nanoelectrospray mass spectrometry. J Neurochem 71: 2465-2476.

Hanger DP, Anderton BH, Noble W. 2009. Tau phosphorylation: The therapeutic challenge for neurodegenerative disease. Trends Molec Med 15: 112-119.

Harada A, Oguchi K, Okabe S, Kuno J, Terada S, Ohshima T, Satoyoshitake R, Takei Y, Noda T, Hirokawa N. 1994. Altered microtubule organization in small-caliber axons of mice lacking tau-protein. Nature 369: 488-491.

Harrison DE, Strong R, Sharp ZD, Nelson JF, Astle CM, Flurkey K, Nadon NL, Wilkinson JE, Frenkel K, Carter CS, et al. 2009. Rapamycin fed late in life extends lifespan in genetically heterogeneous mice. Nature 460: 392-395.

Hasegawa M, Smith MJ, Goedert M. 1998. Tau proteins with FTDP-17 mutations have a reduced ability to promote microtubule assembly. FEBS Lett 437: 207-210.

Hellal F, Hurtado A, Ruschel J, Flynn KC, Laskowski CJ, Umlauf M, Kapitein LC, Strikis D, Lemmon V, Bixby J, et al. 2011. Microtubule stabilization reduces scarring and causes axon regeneration after spinal cord injury. Science 331: 928-931.

Hempen B, Brion JP. 1996. Reduction of acetylated $\alpha$-tubulin immunoreactivity in neurofibrillary tanglebearing neurons in Alzheimer's disease. J Neuropatho Exp Neurol 55: 964-972.

Hernandez F, Borrell J, Guaza C, Avila J, Lucas JJ. 2002. Spatial learning deficit in transgenic mice that conditionally over-express GSK-3 beta in the brain but do not form tau filaments. J Neurochem 83: 1529-1533.

Hong M, Zhukareva V, Vogelsberg-Ragaglia V, Wszolek Z, Reed L, Miller BI, Geschwind DH, Bird TD, McKeel D, Goate A, et al. 1998. Mutation-specific functional impairments in distinct Tau isoforms of hereditary FTDP-17. Science 282: 1914-1917.

Hutton M, Lendon CL, Rizzu P, Baker M, Froelich S, Houlden $\mathrm{H}$, Pickering-Brown S, Chakraverty S, Isaacs A, Grover A, et al. 1998. Association of missense and $5^{\prime}$-splice-site mutations in tau with the inherited dementia FTDP-17. Nature 393: 702-705.

Ikegami S, Harada A, Hirokawa N. 2000. Muscle weakness, hyperactivity, and impairment in fear conditioning in tau-deficient mice. Neurosci Lett 279: 129-132.

Imahori K, Uchida T. 1997. Physiology and pathology of tau protein kinases in relation to Alzheimer's disease. J Biochem 121: 179-188.

Ishihara T, Hong M, Zhang B, Nakagawa Y, Lee MK, Trojanowski JQ, Lee VMY. 1999. Age-dependent emergence and progression of a tauopathy in transgenic mice overexpressing the shortest human tau isoform. Neuron 24: $751-762$.
Ittner LM, Ke YD, Delerue F, Bi MA, Gladbach A, van Eersel J, Wolfing H, Chieng BC, Christie MJ, Napier IA, et al. 2010. Dendritic function of tau mediates amyloid-beta toxicity in Alzheimer's disease mouse models. Cell 142: 387-397.

Jack CR, Knopman DS, Jagust WJ, Shaw LM, Aisen PS, Weiner MW, Petersen RC, Trojanowski JQ. 2010. Hypothetical model of dynamic biomarkers of the Alzheimer's pathological cascade. Lancet Neurol 9: 119-128.

Jeganathan S, von Bergen M, Mandelkow EM, Mandelkow E. 2008. The natively unfolded character of Tau and its aggregation to Alzheimer-like paired helical filaments. Biochemistry 47: 10526-10539.

Kamal A, Thao L, Sensintaffar J, Zhang L, Boehm MF, Fritz LC, Burrows FJ. 2003. A high-affinity conformation of Hsp90 confers tumour selectivity on Hsp90 inhibitors. Nature 425: 407-410.

Kang J, Lemaire HG, Unterbeck A, Salbaum JM, Masters CL, Grzeschik KH, Multhaup G, Beyreuther K, Mullerhill B. 1987. The precursor of alzheimers-disease amyloid-a4 protein resembles a cell-surface receptor. Nature 325: 733-736.

Kar S, Fan J, Smith MJ, Goedert M, Amos LA. 2003. Repeat motifs of tau bind to the insides of microtubules in the absence of taxol. EMBO J 22: 70-77.

Khlistunova I, Biernat J, Wang YP, Pickhardt M, von Bergen M, Gazova Z, Mandelkow E, Mandelkow M. 2006. Inducible expression of tau repeat domain in cell models of tauopathy-Aggregation is toxic to cells but can be reversed by inhibitor drugs. J Biol Chem 281: 1205-1214.

Kidd M. 1963. Paired helical filaments in electron microscopy of alzheimers disease. Nature 197: 192-193.

Kopke E, Tung YC, Shaikh S, Alonso AD, Iqbal K, GrundkeIqbal I. 1993. Microtubule-associated protein-tauabnormal phosphorylation of a non-paired helical filament pool in alzheimer-disease. J Biol Chem 268: 24374-24384.

Ksiezak-Reding H, Liu WK, Yen SH. 1992. Phosphate analysis and dephosphorylation of modified tau associated with paired helical filaments. Brain Res 597: 209-219.

Le Corre S, Klafki HW, Plesnila N, Hubinger G, Obermeier A, Sahagun H, Monse B, Seneci P, Lewis J, Eriksen J, et al. 2006. An inhibitor of tau hyperphosphorylation prevents severe motor impairments in tau transgenic mice. Proc Natl Acad Sci 103: 9673-9678.

Lee VMY, Balin BJ, Otvos L, Trojanowski JQ. 1991. A68—A major subunit of paired helical filaments and derivatized forms of normal-tau. Science 251: 675-678.

Lee VMY, Goedert M, Trojanowski JQ. 2001. Neurodegenerative tauopathies. Annu Rev Neurosci 24: 1121-1159.

Lee G, Thangavel R, Sharma VM, Litersky JM, Bhaskar K, Fang SM, Do LH, Andreadis A, Van Hoesen G, Ksiezak-Reding H. 2004. Phosphorylation of tau by fyn: Implications for Alzheimer's disease. J Neurosci 24: 2304-2312.

Lefebvre T, Ferreira S, Dupont-Wallois L, Bussiere T, Dupire MJ, Delacourte A, Michalski JC, Caillet-Boudin ML. 2003. Evidence of a balance between phosphorylation and O-GlcNAc glycosylation of Tau proteins-a role in nuclear localization. Biochim Biophys Acta-General Subjects 1619: 167-176. 
V.M-Y. Lee et al.

Liu F, Iqbal K, Grundke-Iqbal I, Hart GW, Gong CX. 2004 O-GlcNAcylation regulates phosphorylation of tau: A mechanism involved in Alzheimer's disease. Proc Natl Acad Sci 101: 10804-10809.

Lucas JJ, Hernandez F, Gomez-Ramos P, Moran MA, Hen R, Avila J. 2001. Decreased nuclear beta-catenin, tau hyperphosphorylation and neurodegeneration in GSK-3 beta conditional transgenic mice. EMBO J 20: 27-39.

Luo WJ, Dou F, Rodina A, Chip S, Kim J, Zhao Q, Moulick K, Aguirre J, Wu N, Greengard P, et al. 2007. Roles of heatshock protein 90 in maintaining and facilitating the neurodegenerative phenotype in tauopathies. Proc Natl Acad Sci 104: 9511-9516.

Mahalingam D, Swords R, Carew JS, Nawrocki ST, Bhalla K, Giles FJ. 2009. Targeting HSP90 for cancer therapy. $\mathrm{Br} \mathrm{J}$ Cancer 100: 1523-1529.

Margittai M, Langen R. 2004. Template-assisted filament growth by parallel stacking of tau. Proc Natl Acad Sci 101: 10278-10283.

Matsuo ES, Shin RW, Billingsley ML, Vandevoorde A, O'Connor M, Trojanowski JQ, Lee VMY. 1994. Biopsyderived adult human brain tau is phosphorylated at many of the same sites as Alzheimers-disease paired helical filament-tau. Neuron 13: 989-1002.

Matsuoka Y, Gray AJ, Hirata-Fukae C, Minami SS, Waterhouse EG, Mattson MP, LaFerla FM, Gozes I, Aisen PS 2007. Intranasal NAP administration reduces accumulation of amyloid peptide and tau hyperphosphorylation in a transgenic mouse model of Alzheimer's disease at early pathological stage. J Mol Neurosci 31: 165-170.

Mazanetz MP, Fischer PM. 2007. Untangling tau hyperphosphorylation in drug design for neurodegenerative diseases. Nat Rev Drug Discov 6: 464-479.

Merrick SE, Trojanowski JQ, Lee VMY. 1997. Selective destruction of stable microtubules and axons by inhibitors of protein serine/threonine phosphatases in cultured human neurons (NT2N cells). J Neurosci 17: 5726-5737.

Metzger-Filho O, Moulin C, de Azambuja E, Ahmad A. 2009. Larotaxel: Broadening the road with new taxanes. Expert Opin Investig Drugs 18: 1183-1189.

Miller RA, Harrison DE, Astle CM, Baur JA, Boyd AR, de Cabo R, Fernandez E, Flurkey K, Javors MA, Nelson JF, et al. 2011. Rapamycin, but not resveratrol or simvastatin, extends life span of genetically heterogeneous mice. $J$ Gerontol A Biol Sci Med Sci 66: 191-201.

Min SW, Cho SH, Zhou YG, Schroeder S, Haroutunian V, Seeley WW, Huang EJ, Shen Y, Masliah E, Mukherjee C, et al. 2010. Acetylation of tau inhibits its degradation and contributes to tauopathy. Neuron 67: 953-966.

Mitchell TW, Nissanov J, Han LY, Mufson EJ, Schneider JA, Cochran EJ, Bennett DA, Lee VMY, Trojanowski JQ, Arnold SE. 2000. Novel method to quantify neuropil threads in brains from elders with or without cognitive impairment. J Histochem Cytochemi 48: 1627-1637.

Morishima-Kawashima M, Hasegawa M, Takio K, Suzuki M, Yoshida H, Titani K, Ihara Y. 1995. Proline-directed and non-proline-directed phosphorylation of Phf-Tau. J Biol Chem 270: 823-829.

Morita T, Sobue K. 2009. Specification of neuronal polarity regulated by local translation of CRMP2 and tau via the mTOR-p70S6K pathway. J Biol Chem 284: 27734-27745.

Nacharaju P, Lewis J, Easson C, Yen S, Hackett J, Hutton M, Yen SH. 1999. Accelerated filament formation from tau protein with specific FTDP-17 missense mutations. J Neuropathol Exp Neurol 58: 545.

Nakashima H, Ishihara T, Suguimoto P, Yokota O, Oshima E, Kugo A, Terada S, Hamamura T, Trojanowski JQ, Lee VMY, et al. 2005. Chronic lithium treatment decreases tau lesions by promoting ubiquitination in a mouse model of tauopathies. Acta Neuropathol 110: 547-556.

Necula M, Kuret J. 2004. Pseudophosphorylation and glycation of tau protein enhance but do not trigger fibrillization in vitro. J Biol Chem 279: 49694-49703.

Nixon RA. 2006. Autophagy in neurodegenerative disease: Friend, foe or turncoat? Trends Neurosci 29: 528-535.

Noble W, Olm V, Takata K, Casey MO, Meyerson J, Gaynor K, LaFrancois J, Wang LL, Kondo T, Davies P, et al. 2003. $\mathrm{Cdk} 5$ is a key factor in tau aggregation and tangle formation in vivo. Neuron 38: 555-565.

Noble W, Planel E, Zehr C, Olm V, Meyerson J, Suleman F, Gaynor K, Wang L, LaFrancois J, Feinstein B, et al. 2005. Inhibition of glycogen synthase kinase-3 by lithium correlates with reduced tauopathy and degeneration in vivo. Proc Natl Acad Sci 102: 6990-6995.

Ojima I, Chen J, Sun L, Borella CP, Wang T, Miller ML, Lin SN, Geng XD, Kuznetsova LR, Qu CX, et al. 2008. Design, synthesis, and biological evaluation of new-generation taxoids. J Med Chem 51: 3203-3221.

Orgogozo JM, Gilman S, Dartigues JF, Laurent B, Puel M, Kirby LC, Jouanny P, Dubois B, Eisner L, Flitman S, et al. 2003. Subacute meningoencephalitis in a subset of patients with AD after A beta 42 immunization. Neurology 61: 46-54.

Oz M, Lorke DE, Hasan M, Petroianu GA. 2011. Cellular and molecular actions of methylene blue in the nervous system. Med Res Rev 31: 93-117.

Panda D, Samuel JC, Massie M, Feinstein SC, Wilson L. 2003. Differential regulation of microtubule dynamics by three- and four-repeat tau: Implications for the onset of neurodegenerative disease. Proc Natl Acad Sci 100: 9548-9553.

Pei JJ, Grundke-Iqbal I, Iqbal K, Bogdanovic N, Winblad B, Cowburn RF. 1998. Accumulation of cyclin-dependent kinase $5(\operatorname{cdk} 5)$ in neurons with early stages of $\mathrm{Alz}$ heimer's disease neurofibrillary degeneration. Brain Res 797: 267-277.

Perez M, Hernandez F, Lim F, Diaz-Nido J, Avila J. 2003. Chronic lithium treatment decreases mutant tau protein aggregation in a transgenic mouse model. J Alzheimer's Disease 5: 301-308.

Petrucelli L, Dickson D, Kehoe K, Taylor J, Snyder H, Grover A, De Lucia M, McGowan E, Lewis J, Prihar G, et al. 2004. CHIP and Hsp70 regulate tau ubiquitination, degradation and aggregation. Hum Mol Genet 13: 703-714.

Phiel CJ, Wilson CA, Lee VMY, Klein PS. 2003. GSK-3 $\alpha$ regulates production of Alzheimer's disease amyloid-beta peptides. Nature 423: 435-439.

Pickhardt M, Gazova Z, von Bergen M, Khlistunova I, Wang YP, Hascher A, Mandelkow EM, Biernat J, Mandelkow E. 
2005. Anthraquinones inhibit tau aggregation and dissolve Alzheimer's paired helical filaments in vitro and in cells. J Biol Chem 280: 3628-3635.

Pickhardt M, Larbig G, Khlistunova I, Coksezen A, Meyer B, Mandelkow EM, Schmidt B, Mandelkow E. 2007. Phenylthiazolyl-hydrazide and its derivatives are potent inhibitors of tau aggregation and toxicity in vitro and in cells. Biochemistry 46: 10016-10023.

Rayasam GV, Tulasi VK, Sodhi R, Davis JA, Ray A. 2009. Glycogen synthase kinase 3: More than a namesake. $\mathrm{Br}$ J Pharmacol 156: 885-898.

Reynolds MR, Reyes JF, Fu YF, Bigio EH, GuillozetBongaarts AL, Berry RW, Binder LI. 2006. Tau nitration occurs at tyrosine 29 in the fibrillar lesions of Alzheimer's disease and other tauopathies. J Neurosci 26: 10636-10645.

Rinne JO, Brooks DJ, Rossor MN, Fox NC, Bullock R, Klunk WE, Mathis CA, Blennow K, Barakos J, Okello AA, et al. 2010. C-11-PiB PET assessment of change in fibrillar amyloid-beta load in patients with Alzheimer's disease treated with bapineuzumab: A phase 2, double-blind, placebo-controlled, ascending-dose study. Lancet Neurol 9: $363-372$.

Roberson ED, Scearce-Levie K, Palop JJ, Yan FR, Cheng IH, Wu T, Gerstein H, Yu GQ, Mucke L. 2007. Reducing endogenous tau ameliorates amyloid beta-induced deficits in an Alzheimer's disease mouse model. Science 316: $750-754$

Rockenstein E, Torrance M, Adame A, Mante M, Bar-on P, Rose JB, Crews L, Masliah E. 2007. Neuroprotective effects of regulators of the glycogen synthase kinase-3 beta signaling pathway in a transgenic model of Alzheimer's disease are associated with reduced amyloid precursor protein phosphorylation. J Neurosci 27: 1981-1991.

Rosenmann H, Grigoriadis N, Karussis D, Boimel M, Touloumi O, Ovadia H, Abramsky O. 2006. Tauopathy-like abnormalities and neurologic deficits in mice immunized with neuronal tau protein. Arch Neurol 63: 1459-1467.

Saloustros E, Mavroudis D, Georgoulias V. 2008. Paclitaxel and docetaxel in the treatment of breast cancer. Expert Opin Pharmacother 9: 2603-2616.

Sarkar S, Floto RA, Berger Z, Imarisio S, Cordenier A, Pasco M, Cook LJ, Rubinsztein DC. 2005. Lithium induces autophagy by inhibiting inositol monophosphatase. $J$ Cell Biol 170: 1101-1111.

Schneider A, Biernat J, von Bergen M, Mandelkow E, Mandelkow EM. 1999. Phosphorylation that detaches tau from microtubules S262 and S214 protects it against aggregation into Alzheimer paired helical filaments. J Neurochem 73: S26.

Shimura H, Schwartz D, Gygi SP, Kosik KS. 2004 CHIP-Hsc70 complex ubiquitinates phosphorylated tau and enhances cell survival. J Biol Chem 279: 4869-4876.

Shiryaev N, Jouroukhin Y, Giladi E, Polyzoidou E, Grigoriadis NC, Rosenmann H, Gozes I. 2009. NAP protects memory, increases soluble tau and reduces tau hyperphosphorylation in a tauopathy model. Neurobiol Dis 34: $381-388$.
Solit DB, Chiosis G. 2008. Development and application of Hsp90 inhibitors. Drug Discovery Today 13: 38-43.

Sparreboom A, vanAsperen J, Mayer U, Schinkel AH, Smit JW, Meijer DKF, Borst P, Nooijen WJ, Beijnen JH, vanTellingen O. 1997. Limited oral bioavailability and active epithelial excretion of paclitaxel (Taxol) caused by Pglycoprotein in the intestine. Proc Natl Acad Sci 94: 2031-2035.

Spittaels K, Van Den Haute C, Van Dorpe J, Geerts H, Mercken M, Bruynseels K, Lasrado R, Vandezande K, Laenen I, Boon T, et al. 2000. Glycogen synthase kinase- 3 beta phosphorylates protein tau and rescues the axonopathy in the central nervous system of human fourrepeat tau transgenic mice. J Biol Chem 275: 4134041349.

Staff RT, Ahearn TS, Murray AD, Benthan P, Seng KM, Wischik C. 2008. Tau aggregation inhibitor (TAI) therapy with rember arrests the trajectory of $\mathrm{rCBF}$ decline in brain regions affected by tau pathology in mild to moderate Alzheimer's disease. Alzheimer's Dementia 4: T775.

Stamer K, Vogel R, Thies E, Mandelkow E, Mandelkow EM. 2002. Tau blocks traffic of organelles, neurofilaments, and APP vesicles in neurons and enhances oxidative stress. J Cell Biol 156: 1051-1063.

Tanimukai H, Kudo T, Tanaka T, Grundke-Iqbal I, Iqbal K, Takeda M. 2009. Novel therapeutic strategies for neurodegenerative disease. Psychogeriatrics 9: 103-109.

Vershinin M, Carter BC, Razafsky DS, King SJ, Gross SP. 2007. Multiple-motor based transport and its regulation by Tau. Proc Natl Acad Sci 104: 87-92.

Wagner U, Utton M, Gallo JM, Miller CCJ. 1996. Cellular phosphorylation of tau by GSK-3 beta influences tau binding to microtubules and microtubule organisation. J Cell Sci 109: 1537-1543.

Wang YP, Martinez-Vicente M, Kruger U, Kaushik S, Wong E, Mandelkow EM, Cuervo AM, Mandelkow E. 2009. Tau fragmentation, aggregation and clearance: The dual role of lysosomal processing. Hum Mol Genet 18: 41534170.

Wen Y, Planel E, Herman M, Figueroa HY, Wang LL, Liu L, Lau LF, Yu WH, Duff KE. 2008. Interplay between cyclin-dependent kinase 5 and glycogen synthase kinase 3 beta mediated by neuregulin signaling leads to differential effects on tau phosphorylation and amyloid precursor protein processing. J Neurosci 28: 26242632.

Wilcock GK. 2010. Bapineuzumab in Alzheimer's disease: Where now? Lancet Neurol 9: 134-136.

Wilcock GK, Esiri MM. 1982. Plaques, tangles and dementia-a quantitative study. J Neurol Sci 56: 343-356.

Wille H, Drewes G, Biernat J, Mandelkow EM, Mandelkow E. 1992. Alzheimer-like paired helical filaments and antiparallel dimers formed from microtubule-associated protein-tau in vitro. J Cell Biol 118: 573-584.

Williams A, Jahreiss L, Sarkar S, Saiki S, Menzies FM, Ravikumar B, Rubinsztein DC. 2006. Aggregate-prone proteins are cleared from the cytosol by autophagy: Therapeutic implications. Curr Topics Dev Biol 76: 89-101.

Wilson DM, Binder LI. 1997. Free fatty acids stimulate the polymerization of tau and amyloid beta peptides-In 
V.M-Y. Lee et al.

vitro evidence for a common effector of pathogenesis in Alzheimer's disease. Am J Pathol 150: 2181-2195.

Wischik CM, Edwards PC, Lai RYK, Roth M, Harrington CR. 1996. Selective inhibition of Alzheimer disease-like tau aggregation by phenothiazines. Proc Natl Acad Sci 93: $11213-11218$.

Yamaguchi H, Ishiguro K, Uchida T, Takashima A, Lemere CA, Imahori K. 1996. Preferential labeling of Alzheimer neurofibrillary tangles with antisera for tau protein kinase (TPK)I glycogen synthase kinase- 3 beta and cyclindependent kinase 5, a component of TPK II. Acta Neuropathol 92: 232-241.

Yang XJ, Seto E. 2008. Lysine acetylation: Codified crosstalk with other posttranslational modifications. Mol Cell 31: 449-461.
Yuzwa SA, Macauley MS, Heinonen JE, Shan XY, Dennis RJ, He YA, Whitworth GE, Stubbs KA, McEachern EJ, Davies GJ, et al. 2008. A potent mechanisminspired O-GlcNAcase inhibitor that blocks phosphorylation of tau in vivo. Nat Chem Biol 4: 483490.

Zhang B, Maiti A, Shively S, Lakhani F, McDonald-Jones G, Bruce J, Lee EB, Xie SX, Joyce S, Li C, et al. 2005. Microtubule-binding drugs offset tau sequestration by stabilizing microtubules and reversing fast axonal transport deficits in a tauopathy model. Proc Natl Acad Sci 102: $227-231$.

Zhang H, Burrows F. 2004. Targeting multiple signal transduction pathways through inhibition of Hsp90. J Mol Med Jmmunol 82: 488-499. 


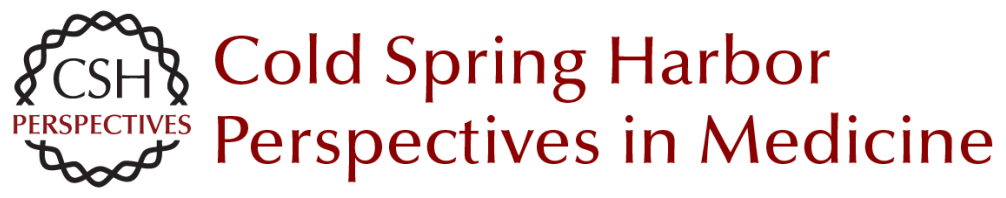

\section{Developing Therapeutic Approaches to Tau, Selected Kinases, and Related Neuronal Protein Targets}

Virginia M-Y. Lee, Kurt R. Brunden, Michael Hutton and John Q. Trojanowski

Cold Spring Harb Perspect Med 2011; doi: 10.1101/cshperspect.a006437

Subject Collection The Biology of Alzheimer Disease

Animal Models of Alzheimer Disease

Frank M. LaFerla and Kim N. Green

Neurovascular Dysfunction and Faulty Amyloid $\beta$ -Peptide Clearance in Alzheimer Disease Abhay P. Sagare, Robert D. Bell and Berislav V. Zlokovic

Treatment Strategies Targeting Amyloid $\beta$-Protein Dale Schenk, Guriqbal S. Basi and Menelas N. Pangalos

The Ubiquitin-Proteasome System and the Autophagic-Lysosomal System in Alzheimer Disease

Yasuo Ihara, Maho Morishima-Kawashima and Ralph Nixon

Neurotoxicity of Amyloid $\beta$-Protein: Synaptic and Network Dysfunction Lennart Mucke and Dennis J. Selkoe

Proteolytic Degradation of Amyloid $\beta$-Protein Takaomi Saido and Malcolm A. Leissring

Brain Imaging in Alzheimer Disease Keith A. Johnson, Nick C. Fox, Reisa A. Sperling, et al.

Symptomatic and Nonamyloid/Tau Based Pharmacologic Treatment for Alzheimer Disease Paul S. Aisen, Jeffrey Cummings and Lon S. Schneider
Alzheimer Disease in 2020

David M. Holtzman, Eckhard Mandelkow and Dennis J. Selkoe

The Genetics of Alzheimer Disease Rudolph E. Tanzi

Fluid Biomarkers in Alzheimer Disease Kaj Blennow, Henrik Zetterberg and Anne M. Fagan

Epidemiology of Alzheimer Disease Richard Mayeux and Yaakov Stern

Biochemistry and Cell Biology of Tau Protein in Neurofibrillary Degeneration Eva-Maria Mandelkow and Eckhard Mandelkow

Biochemistry of Amyloid $\beta$-Protein and Amyloid Deposits in Alzheimer Disease Colin L. Masters and Dennis J. Selkoe

The Neuropsychological Profile of Alzheimer Disease

Sandra Weintraub, Alissa H. Wicklund and David P. Salmon

Apolipoprotein E and Apolipoprotein E Receptors: Normal Biology and Roles in Alzheimer Disease David M. Holtzman, Joachim Herz and Guojun Bu

For additional articles in this collection, see http://perspectivesinmedicine.cshlp.org/cgi/collection/ 